\title{
Gooseneck barnacles (Lepas spp.) ingest microplastic debris in the North Pacific Subtropical Gyre
}

Substantial quantities of small plastic particles, termed "microplastic," have been found in many areas of the world ocean, and have accumulated in particularly high densities on the surface of the subtropical gyres. While plastic debris has been documented on the surface of the North Pacific Subtropical Gyre (NPSG) since the early 1970s, the ecological implications remain poorly understood. Organisms associated with floating objects, termed the "rafting assemblage," are an important component of the NPSG ecosystem. These objects are often dominated by abundant and fast-growing gooseneck barnacles (Lepas spp.), which predate on plankton and larval fishes at the sea surface. To assess the potential effects of microplastic on the rafting community, we examined the gastrointestinal tracts of 385 barnacles collected from the NPSG for evidence of plastic ingestion. We found that $33.5 \%$ of the barnacles had plastic particles present in their gastrointestinal tract, ranging from one plastic particle to a maximum of 30 particles. Particle ingestion was positively correlated to capitulum length, and no blockage of the stomach or intestines was observed. The majority of ingested plastic was polyethylene, with polypropylene and polystyrene also present. Our results suggest that barnacle ingestion of microplastic is relatively common, with unknown trophic impacts on the rafting community and the NPSG ecosystem. 
1 Miriam C. Goldstein*, Scripps Institution of Oceanography, University of California San Diego,

2 La Jolla CA, USA; California Sea Grant, La Jolla CA USA (current institution)

3 Deborah S. Goodwin, Sea Education Association, P.O. Box 6, Woods Hole, MA USA

4 *Corresponding author

\section{$5 \quad$ Introduction}

6 Oceanic litter, termed "marine debris" or "plastic pollution," is a matter of increasing

7 scientific and public concern (STAP-GEF 2011, U.S. Environmental Protection Agency 2011,

8 Convention on Biological Diversity and STAP-GEF 2012). The durability and longevity that

9 make plastic a useful substance also leads to its persistence in the marine environment, with

10 consequences that include entanglement, damage to habitats, species transport, and ingestion

11 (National Research Council 2009). One study estimated that more than 267 species have been

12 documented to ingest plastic (Allsopp et al. 2006), including mammals (Eriksson and Burton

13 2003, Jacobsen et al. 2010), seabirds (Moser and Lee 1992, Ryan 2008, van Franeker et al. 2011),

14 turtles (Schuyler et al. 2013), and a wide variety of fishes (Possatto et al. 2011, Lusher et al.

15 2013, Anastasopoulou et al. 2013). Negative effects of plastic ingestion may include intestinal

16 blockage, diminished feeding stimulus, lowered steroid hormone levels, delayed ovulation and

17 reproductive failure (Azzarello and Van Vleet 1987, Derraik 2002). Because oceanic plastic

18 debris can contain high levels of hydrophobic toxins (Endo et al. 2005, Frias et al. 2010, Rios et

19 al. 2010, Rochman et al. 2013), ingestion of plastic debris may also increase toxic exposure

20 (Teuten et al. 2009, Gassel et al. 2013).

21 Most plastic ingestion has been documented in vertebrates (Convention on Biological

22 Diversity and STAP-GEF 2012), but the extent of plastic ingestion in marine invertebrates

23 remains poorly known. Laboratory experiments suggest that many invertebrate species ingest

24 plastic (reviewed in Wright et al. 2013). Suspended plastic particles (2-60 $\mu \mathrm{m}$ in diameter) were 
successfully fed to calanoid copepods, cladocerans, and salps in the context of studying particle size selectivity (Burns 1968, Wilson 1973, Frost 1977, Kremer and Madin 1992). In laboratory studies focused specifically on the incidence of plastic ingestion, plastic particles were readily consumed by an assortment of zooplankton (Cole et al. 2013) and benthic invertebrates

(Thompson et al. 2004, Browne et al. 2008, Graham and Thompson 2009, Wegner et al. 2012, von Moos et al. 2012, Besseling et al. 2013). However, the evidence from natural ecosystems is far sparser. To date, we are aware of only three studies that have found in situ plastic ingestion in invertebrates: sandhopper amphipods (Talitrus saltator; Ugolini et al. 2013), Norway lobster (Nephrops norvegicus; Murray and Cowie 2011), and flying squid (Ommastrephes bartrami; Day 1988 cited in Laist 1997).

Though plastic pollution has been documented in the North Atlantic and North Pacific subtropical gyres since the early 1970s (Carpenter and Smith 1972, Wong et al. 1974, Day and Shaw 1987, Moore et al. 2001, Law et al. 2010, Goldstein et al. 2012), the ecological implications have been relatively little studied. In this open ocean ecosystem, the majority of marine debris are small particles (termed "microplastic," less than $5 \mathrm{~mm}$ in diameter) that float at the sea surface (Hidalgo-Ruz et al. 2012), though wind mixing moves some particles deeper (Kukulka et al. 2012). Floating plastics in these areas are primarily comprised of polyethylene, with polypropylene and polystyrene also present (Rios et al. 2007, Goldstein 2012). Ingestion has been found in surface-feeding seabirds (Fry et al. 1987, Avery-Gomm et al. 2012) and epipelagic and mesopelagic fishes (Boerger et al. 2010, Davison and Asch 2011, Jantz et al. 2013, Choy and Drazen 2013), but the biota most likely to be impacted by microplastic pollution is the neuston, a specialized community associated with the air-sea interface which includes both zooplankton and substrate-associated rafting organisms (Cheng 1975).

Rafting organisms in the open ocean are increasingly associated with floating plastic debris, which has supplemented natural substrates such as pumice and macroalgae (Thiel and 
Gutow 2005a). Two species of lepadomorph barnacles (Lepas anatifera and Lepas pacifica) are widespread throughout the North Pacific Subtropical Gyre (NPSG) and frequently dominate the rafting assemblage (Tsikhon-Lukanina et al. 2001). (A third species, Lepas (Dosima) fascularis, forms its own float at the end of the juvenile stage and drifts independently, and is therefore not a major component of the rafting assemblage; Newman and Abbott 1980.) These barnacles are omnivorous, feeding opportunistically on the neustonic zooplankton, and are said to "hold a singular position in having more sources of food to draw upon than any other organisms in the neuston (Bieri 1966)." The barnacles are themselves preyed upon by omnivorous epipelagic crabs and the rafting nudibranch Fiona pinnata (Bieri 1966, Davenport 1992).

In this study, we hypothesized that Lepas' indiscriminate feeding strategy and position at the sea surface could cause this species to ingest microplastic, with unknown implications for NPSG ecology. To this end, we examined the gastrointestinal tracts of 385 Lepas from the NPSG for evidence of microplastic ingestion.

\section{$\underline{\text { Methods }}$}

Floating debris items with attached gooseneck barnacles (Fig 1A) were opportunistically collected during the 2009 Scripps Environmental Accumulation of Plastic Expedition (SEAPLEX) and two 2012 Sea Education Association (SEA) research cruises onboard the SSV Robert C. Seamans: S242, an undergraduate voyage from Honolulu, HI to San Francisco, CA (mid-June to mid-July 2012), and S243, the Plastics at SEA: North Pacific Expedition from San Diego, CA to Honolulu, HI (early October to mid-November 2012; Fig 1A). Collection occurred by several means, including 1) from the vessel using a long-handled dip net (335 $\mu \mathrm{m}$ mesh, $0.5 \mathrm{~m}$ diameter mouth); 2) incidentally during neuston net (335 $\mu \mathrm{m}$ mesh, $0.5 \times 1.0 \mathrm{~m}$ mouth) tows at the air-sea interface; and 3) from small boat surveys within $0.5 \mathrm{~km}$ of each vessel when sea conditions were calm. No specific permissions were required for these samples, since they were 
taken in international waters and did not involve protected species. Seven debris items were sampled on SEAPLEX and 29 by SEA (5 during S242 and 24 on S243). Stations within $8.5 \mathrm{~km}$ of each other were combined for a total of 19 sampling locations within in the northeastern Pacific Ocean (Fig 2, Table 1).

During SEAPLEX, the entire piece of debris with attached barnacles was preserved in 5\% Formalin buffered with sodium borate. When the item was too large to be preserved (e.g., a fishing buoy), barnacles were removed and preserved separately. On SEA cruises, as many barnacles as possible to a maximum of 50 were removed from the debris object and preserved in $10 \%$ ethanol. Where feasible, a fragment of the item itself was also sampled.

In the laboratory, capitulum length was measured using a ruler and species identification (L. anatifera or L. pacifica) determined for all intact individuals (Fig 1B). Barnacles less than 0.8 $\mathrm{cm}$ were present, but not sampled in this study. Barnacles greater than approximately $0.8 \mathrm{~cm}$ in length were dissected and the contents of their stomach and intestinal tract examined under a dissecting microscope (6-25x magnification as needed). Barnacles were cut open with a scalpel, and the intestinal tract removed and placed in a separate section of the petri dish. The intestinal tract was opened lengthwise, and the contents examined systematically both visually and with forceps. To avoid cross-contamination between samples, each barnacle was dissected in unique, clean petri dish and the scalpel was thoroughly rinsed with deionized water between each samples. Only microplastic fragments and monofilament that were clearly present inside the intestine were considered. Fine microfibers were discounted, as they could not be distinguished from airborne contamination. Because the vast majority of microplastic found were relatively large degraded fragments $(>0.5 \mathrm{~mm}$ in diameter), visual examination was sufficient to confirm that the microplastic was present in the intestine, and not a result of contamination (Fig 1C). Plastic particles found in the stomach or intestine were quantified, photographed digitally against a ruler for size assessment, rinsed with fresh water and stored in a glass vial for later 
analyses. The maximum diameter (feret diameter) and two-dimensional area of each particle were digitally measured with the software package NIH ImageJ (Rasband 2012). On the SEAPLEX cruise in 2009, we also measured the diameter and area of all plastic particles captured in surfacetowed plankton nets (number of particles $=30,518$ ) using NIH ImageJ-based tools in the Zooprocess software calibrated against manual measurements (Gilfillan et al. 2009, Gorsky et al. 2010).

We identified the type of plastic recovered from a randomly selected subset of barnacles (Barnacles N=42; particles N=219). A Raman spectrometer (PeakSeeker Pro-785 with AmScope operated at $10-50 \mathrm{~mW}$ and 5-20 second integration time; Raman Systems MII, Inc/Agiltron, Inc., Woburn, MA) and associated RSIQ software were used to identify plastic type. The Raman spectrum for each plastic piece was compared to a reference library of known plastic types for identification. Particles of clear, white, gray and pale-colored (light blues and greens, oranges and yellows) plastics yielded high quality Raman spectra and were readily identifiable. Those that were darker (medium to dark blues, reds and greens as well as black; $35 \%$ of particles subjected to Raman spectroscopy) were heated by the laser beam and melted even at the lowest possible power and integration time settings, resulting in no usable spectra. We also identified a subset of the debris items to which the barnacles were attached. Fragments of 18 objects were collected for analysis, but 6 could not be identified due to darker pigmentation due to melting under the laser. Statistics and figures were generated with the R statistical environment, version R-2.15.1 (R Development Core Team 2012) and QuantumGIS, version 1.8.0-Lisboa (QGIS Development Team 2013).

\section{$121 \quad \underline{\text { Results }}$}

Of the 385 barnacles examined, 129 individuals (33.5\%) had ingested plastic (Fig 2, Table

123 1). These included 243 Lepas anatifera and 85 Lepas pacifica (57 barnacles could not be 
124

125

126

127

identified to species), of which 90 L. anatifera, 34 L. pacifica, and 5 Lepas spp. contained plastic. Forty-one of the barnacles that ingested plastic had one plastic particle in their stomach or intestines, 26 individuals had two particles, and 57 individuals contained three or more particles, to a maximum of 30 particles (Fig 3A).

Overall, the number of ingested particles was positively correlated to capitulum length (Kendall's tau $=0.099, \mathrm{p}=0.015$ ). However, when we considered only barnacles that had ingested plastic, the correlation between plastic ingestion and capitulum length was not significant (Kendall's tau=-0.080, $\mathrm{p}=0.229$ ). Individuals with a capitulum length between 2 and $3 \mathrm{~cm}$ consumed the greatest number plastic particles (Fig 3B). With the exception of one individual, all the barnacles that consumed plastic had a capitulum length of $1.7 \mathrm{~cm}$ or greater.

In total, 518 plastic particles were recovered from barnacle digestive tracts. Of these, $99 \%$ were degraded fragments and $1 \%$ were monofilament line. None of the pre-production pellets known as "nurdles" were found. The median diameter of ingested particles was $1.41 \mathrm{~mm}$, and the median surface area $1.00 \mathrm{~mm}^{2}$, smaller than the median diameter of $1.78 \mathrm{~mm}$ and median surface area of $1.27 \mathrm{~mm}^{2}$ for all particles collected in nets during 2009 (Fig 4, KolmogorovSmirnov test $\mathrm{p}<0.001)$. The smallest particle ingested by barnacles had a maximum diameter of $0.609 \mathrm{~mm}$ and the largest (a long thin fragment) a maximum diameter of $6.770 \mathrm{~mm}$. No blockage of the stomach or intestine was observed, and particles did not accumulate in any area of the digestive tract. All particles were of a plausible size to pass through the anus.

Of the randomly selected subset of 219 ingested plastic particles that were analyzed for plastic type, $58.4 \%$ were polyethylene, $5.0 \%$ were polypropylene, and $1.4 \%$ were polystyrene. As noted in the Methods section, we were unable to identify $35 \%$ of the subset due to darker pigmentation in these particles, which caused melting under the Raman spectrophotometer. Of the 29 barnacles that had ingested more than one piece of plastic, $66 \%$ contained more than one type of plastic. The plastic types of 12 floating debris items to which barnacles were attached 
were more diverse than those of ingested particles. Four substrates were polystyrene, 3 were polyethylene, 2 were polypropylene, 2 were polyethylene terephthalate, and one was tire rubber.

\section{$\underline{\text { Discussion }}$}

Our results show that $33.5 \%$ of lepadid barnacles collected from the NPSG ingested microplastic, and that the sizes and types of ingested particles were approximately representative of microplastic found on the NPSG surface. Plastic ingestion in these barnacles may therefore be explained by non-selective suspension feeding while exposed to high concentrations of microplastic.

The percentage of barnacles observed with ingested plastic in this study is higher than the 9.2\% found in NPSG micronektonic fishes (Davison and Asch 2011) and the 19-24.5\% found in larger mesopelagic fishes (Jantz et al. 2013, Choy and Drazen 2013). It is likely that barnacles encounter microplastic more frequently than vertically migrating mesopelagic fishes due to the barnacles' consistent location at the air-sea interface. Since barnacles probably clear their guts in a matter of hours (Ritz 2008), it is likely that a higher percentage of the barnacle population interacts with microplastic than is presented here. Unfortunately, due to logistical considerations on both cruises, barnacle samples were not usually concurrent with neuston tows. Since neustonic microplastic is highly spatially heterogeneous (Ryan et al. 2009), we are thus unable directly compare neustonic microplastic concentrations with incidence of barnacle ingestion. However, the sampling area is known to contain high concentrations of neustonic microplastic (Moore et al. 2001, Goldstein et al. 2012).

The objects to which the barnacles are attached may also shed microplastic particles, increasing the likelihood of those particles being ingested by the local rafting community. However, the microplastics ingested by individual barnacles in this study were of multiple plastic types and colors, suggesting they are taking in particles from the surrounding water rather than 
solely from the substrate to which they are attached. Lepadid barnacles are known to be very nonselective feeders. For example, L.anatifera opportunistically ingests a wide variety of zooplankton and even fills its gut with sand when stranded on the beach (Howard and Scott 1959). L. anatifera can also readily consume large prey items up to $5 \mathrm{~mm}$ in diameter, larger than the majority of microplastic debris (Patel 1959). Less is known about the feeding habits of $L$. pacifica, but it is presumed to have a similar feeding ecology as L. anatifera and other lepadid barnacles (Crisp and Southward 1961, Cheng and Lewin 1976). To avoid difficulties in identifying plastic with darker pigmentation, future studies might consider supplementing Raman spectroscopy with density analysis (Moret-Ferguson et al. 2010), or utilizing Fourier transform infrared spectroscopy when available (Rios et al. 2007, Goldstein 2012).

We found only one barnacle with a capitulum length of less than $1.7 \mathrm{~cm}$ that had ingested plastic. This observation implies that barnacles may need to reach a certain size before plastic ingestion is possible, perhaps due to the size of the cirri or oral opening. However, our study used visual methods to identify microplastic in barnacle gut contents, and spectroscopic methods or chemical digestion of the tissue are needed to positively identify plastic particles smaller than approximately $300 \mu \mathrm{m}$ (Claessens et al. 2011, Hidalgo-Ruz et al. 2012). It is therefore possible that plastic ingestion in the smaller barnacles was not detected in this study. Assessing the ecological significance of plastic ingestion in pelagic invertebrates and fishes remains a challenge. Even in relatively well-studied species, it has been difficult to link plastic ingestion to mortality. For example, two studies of Laysan and black-footed albatross chicks did not find a linkage between cause of death and plastic ingestion (Sileo et al. 1990, Sievert and Sileo 1993), though a third study linked plastic ingestion with lower body weight in adult birds (Spear et al. 1995). Most studies on invertebrates have been relatively short-term investigations that have not found acute negative effects (Thompson et al. 2004, Browne et al. 2008, Graham and Thompson 2009), with the exception of an inflammatory immune response in 
mussels (von Moos et al. 2012). In zooplankton, the presence of non-edible particles can reduce the rate of feeding on edible particles (Huntley et al. 1983, Ayukai 1987, Cole et al. 2013), and physical interference with sensory apparatus may occur in very high-plastic environments (Cole et al. 2013). The lepadid barnacles in this study did not show evidence of acute harm (e.g., intestinal blockage or ulceration), though negative long-term effects cannot be ruled out. Plastic ingestion may also lead to increased body loads of persistent organic pollutants in both vertebrates and invertebrates (Teuten et al. 2009, Yamashita et al. 2011, Gassel et al. 2013, Besseling et al. 2013), but it is not known whether this occurs in barnacles, or has populationlevel ramifications in any taxa (Gouin et al. 2011). For example, a modeling study based on lugworms (Arenicola marina) did not find a significant toxicological risk from plastic-adsorbed pollutants (Koelmans et al. 2013). Because L.anatifera appear to survive well in the laboratory (Patel 1959), more detailed studies may be possible.

If barnacles are an important prey item, it is possible that their ingestion of plastic particles could transfer plastic or pollutants through the food web. Plastic particles found in fur seals (Eriksson and Burton 2003), piscivorous fishes (Davison and Asch 2011), and crabs (Farrell and Nelson 2013) have been linked to consumption of contaminated prey. The only documented predator of rafting Lepas spp. is the nudibranch Fiona pinnata (Bieri 1966), though it is probable that omnivorous rafting crabs also consume barnacles to some extent (Davenport 1992, Frick et al. 2011). Relatively low rates of predation on these barnacles may explain Lepas ' place as one of the most abundant members of the North Pacific subtropical rafting community (Newman and Abbott 1980, Thiel and Gutow 2005b). For example, one study found that L. pacifica was excluded from nearshore kelp forests by the fish Oxyjulis californica, but was able to inhabit floating kelp paddies in high densities when O. californica was absent (Bernstein and Jung 1979). Studies of the diets of fishes associated with Fish Aggregating Devices (FADs) have found that fishes associated with floating objects rarely feed directly on the fouling community (Ibrahim et 
al. 1996, Nelson 2003, Vassilopoulou et al. 2004). The likelihood of predators ingesting plastic by

feeding on barnacles may therefore be relatively low.

While plastic ingestion in taxa such as sea turtles (Schuyler et al. 2013) and cetaceans

(Jacobsen et al. 2010) is clearly detrimental, the implications of widespread plastic ingestion in

Lepas remain uncertain. Since little is known about the trophic structure and connectivity of both the rafting and drifting components of the neuston, additional studies are necessary to determine the impacts of microplastic ingestion on the rafting community and the larger pelagic ecosystem.

\section{$\underline{\text { Acknowledgements }}$}

We thank the captain, crews, and students of the SEAPLEX cruise on the R/V New Horizon and Sea Education Association cruises S-242 and S-243 on the SSV Robert C. Seamans. Assistance from L. Sala, M.D. Ohman, and E. Zettler made this project possible.

\section{$\underline{\text { References }}$}

Allsopp, M., A. Walters, D. Santillo, and P. Johnston. 2006. Plastic debris in the world's oceans. 44 pp. Greenpeace.

Anastasopoulou, A., C. Mytilineou, C. J. Smith, and K. N. Papadopoulou. 2013. Plastic debris ingested by deep-water fish of the Ionian Sea (Eastern Mediterranean). Deep Sea Research Part I: Oceanographic Research Papers 74:11-13.

Avery-Gomm, S., P. D. O’Hara, L. Kleine, V. Bowes, L. K. Wilson, and K. L. Barry. 2012. Northern fulmars as biological monitors of trends of plastic pollution in the eastern North Pacific. Marine Pollution Bulletin 64:1776-1781.

Ayukai, T. 1987. Discriminate feeding of the calanoid copepod Acartia clausi in mixtures of phytoplankton and inert particles. Marine Biology 94:579-587.

Azzarello, M. Y., and E. S. Van Vleet. 1987. Marine birds and plastic pollution. Marine Ecology Progress Series 37:295-303.

Bernstein, B., and N. Jung. 1979. Selective pressures and coevolution in a kelp canopy community in southern California. Ecological Monographs 49:335-355.

Besseling, E., A. Wegner, E. M. Foekema, M. J. van den Heuvel-Greve, and A. A. Koelmans. 2013. Effects of microplastic on fitness and PCB bioaccumulation by the lugworm Arenicola marina (L.). Environmental Science \& Technology 47:593-600.

Bieri, R. 1966. Feeding preferences and rates of the snail, Ianthina prolongata, the barnacle, Lepas anserifera, the nudibranchs, Glaucus atlanticus and Fiona pinnata, and the food web in the marine neuston. Publications of the Seto Marine Biological Laboratory 14:161-170. 
Boerger, C. M., G. L. Lattin, S. L. Moore, and C. J. Moore. 2010. Plastic ingestion by planktivorous fishes in the North Pacific Central Gyre. Marine Pollution Bulletin 60:2275-2278.

Browne, M. A., A. Dissanayake, T. S. Galloway, D. M. Lowe, and R. C. Thompson. 2008. Ingested microscopic plastic translocates to the circulatory system of the mussel, Mytilus edulis (L). Environmental Science \& Technology 42:5026-31.

Burns, C. W. 1968. The relationship between body size of filter-feeding Cladocera and the maximum size of particle ingested. Limnology and Oceanography 13:675-678.

Carpenter, E. J., and K. L. Smith. 1972. Plastics on the Sargasso Sea surface. Science 175:1240.

Cheng, L. 1975. Marine pleuston-animals at the sea-air interface. Oceanography and Marine Biology: An Annual Review 13:181-212.

Cheng, L., and R. A. Lewin. 1976. Goose barnacles (Cirripedia: Thoracica) on flotsam beached at La Jolla, California. Fishery Bulletin 74.

Choy, C. A., and J. C. Drazen. 2013. Plastic for dinner? Observations of frequent debris ingestion by pelagic predatory fishes from the central North Pacific. Marine Ecology Progress Series 485:155-163.

Claessens, M., S. D. Meester, L. V. Landuyt, K. D. Clerck, and C. R. Janssen. 2011. Occurrence and distribution of microplastics in marine sediments along the Belgian coast. Marine Pollution Bulletin 62:2199-2204.

Cole, M., P. Lindeque, E. Fileman, C. Halsband, R. Goodhead, J. Moger, and T. S. Galloway. 2013. Microplastic ingestion by zooplankton. Environmental Science \& Technology.

Convention on Biological Diversity, and STAP-GEF. 2012. Impacts of Marine Debris on Biodiversity: Current Status and Potential Solutions. 61 pp. Secretariat of the Convention on Biological Diversity and the Scientific and Technical Advisory Panel-GEF, Montreal.

Crisp, D. J., and A. J. Southward. 1961. Different types of cirral activity of barnacles. Philosophical Transactions of the Royal Society of London. Series B, Biological Sciences 243:271-307.

Davenport, J. 1992. Observations on the ecology, behaviour, swimming mechanism and energetics of the neustonic grapsid crab, Planes minutus. Journal of the Marine Biological Association of the United Kingdom 72:611-620.

Davison, P., and R. G. Asch. 2011. Plastic ingestion by mesopelagic fishes in the North Pacific Subtropical Gyre. Marine Ecology Progress Series 432:173-180.

Day, R. H., and D. G. Shaw. 1987. Patterns in the abundance of pelagic plastic and tar in the north Pacific Ocean, 1976-1985. Marine Pollution Bulletin 18:311-316.

Derraik, J. G. B. 2002. The pollution of the marine environment by plastic debris: a review. Marine Pollution Bulletin 44:842-852.

Endo, S., R. Takizawa, K. Okuda, H. Takada, K. Chiba, H. Kanehiro, H. Ogi, R. Yamashita, and T. Date. 2005. Concentration of polychlorinated biphenyls (PCBs) in beached resin pellets: Variability among individual particles and regional differences. Marine Pollution Bulletin 50:1103-1114.

Eriksson, C., and H. Burton. 2003. Origins and biological accumulation of small plastic particles in fur seals from Macquarie Island. AMBIO: A Journal of the Human Environment 32:380-384.

Farrell, P., and K. Nelson. 2013. Trophic level transfer of microplastic: Mytilus edulis (L.) to Carcinus maenas (L.). Environmental Pollution 177:1-3.

Van Franeker, J. A., C. Blaize, J. Danielsen, K. Fairclough, J. Gollan, N. Guse, P.-L. Hansen, M. Heubeck, J.-K. Jensen, G. Le Guillou, B. Olsen, K.-O. Olsen, J. Pedersen, E. W. M. Stienen, and D. M. Turner. 2011. Monitoring plastic ingestion by the northern fulmar Fulmarus glacialis in the North Sea. Environmental Pollution 159:2609-2615. 
304

305

306

307

308

309

310

311

312

313

314

315

316

317

318

319

320

321

322

323

324

325

326

327

328

329

330

331

332

333

334

335

336

337

338

339

340

341

342

343

344

345

346

347

348

349

350

351

352
Frias, J. P. G. L., P. Sobral, and A. M. Ferreira. 2010. Organic pollutants in microplastics from two beaches of the Portuguese coast. Marine Pollution Bulletin 60:1988-1992.

Frick, M. G., K. Kopitsky, A. B. Bolten, K. A. Bjorndal, and H. R. Martins. 2011. Sympatry in grapsoid crabs (genera Planes and Plagusia) from olive ridley sea turtles (Lepidochelys olivacea), with descriptions of crab diets and masticatory structures. Marine Biology 158:1699-1708.

Frost, B. W. 1977. Feeding behavior of Calanus pacificus in mixtures of food particles. Limnology and Oceanography 22:472-491.

Fry, D. M., S. I. Fefer, and L. Sileo. 1987. Ingestion of plastic debris by Laysan Albatrosses and Wedge-tailed Shearwaters in the Hawaiian Islands. Marine Pollution Bulletin 18:339-343.

Gassel, M., S. Harwani, J.-S. Park, and A. Jahn. 2013. Detection of nonylphenol and persistent organic pollutants in fish from the North Pacific Central Gyre. Marine Pollution Bulletin. Published online 5 June 2013.

Gilfillan, L. R., M. D. Ohman, M. J. Doyle, and W. Watson. 2009. Occurrence of plastic microdebris in the southern California Current system. CalCOFI Report 50:123-133.

Goldstein, M. C. 2012. Abundance and ecological implications of microplastic debris in the North Pacific Subtropical Gyre. Ph.D. thesis, Scripps Institution of Oceanography, University of California San Diego, La Jolla, CA.

Goldstein, M. C., M. Rosenberg, and L. Cheng. 2012. Increased oceanic microplastic debris enhances oviposition in an endemic pelagic insect. Biology Letters 8:817-820.

Gorsky, G., M. D. Ohman, M. Picheral, S. Gasparini, L. Stemmann, J.-B. Romagnan, A. Cawood, S. Pesant, C. Garcia-Comas, and F. Prejger. 2010. Digital zooplankton image analysis using the ZooScan integrated system. Journal of Plankton Research 32:285-303.

Gouin, T., N. Roche, R. Lohmann, and G. Hodges. 2011. A thermodynamic approach for assessing the environmental exposure of chemicals absorbed to microplastic. Environmental Science \& Technology 45:1466-1472.

Graham, E. R., and J. T. Thompson. 2009. Deposit- and suspension-feeding sea cucumbers (Echinodermata) ingest plastic fragments. Journal of Experimental Marine Biology and Ecology 368:22-29.

Hidalgo-Ruz, V., L. Gutow, R. C. Thompson, and M. Thiel. 2012. Microplastics in the marine environment: a review of the methods used for identification and quantification. Environmental Science \& Technology 46:3060-3075.

Howard, G., and H. Scott. 1959. Predaceous feeding in two common gooseneck barnacles. Science 129:717-718.

Huntley, M. E., K.-G. Barthel, and J. L. Star. 1983. Particle rejection by Calanus pacificus: discrimination between similarly sized particles. Marine Biology 74:151-160.

Ibrahim, S., M. A. Ambak, L. Shamsudin, and M. Z. Samsudin. 1996. Importance of fish aggregating devices (FADs) as substrates for food organisms of fish. Fisheries Research 27:265-273.

Jacobsen, J. K., L. Massey, and F. Gulland. 2010. Fatal ingestion of floating net debris by two sperm whales (Physeter macrocephalus). Marine Pollution Bulletin 60:765-767.

Jantz, L. A., C. L. Morishige, G. L. Bruland, and C. A. Lepczyk. 2013. Ingestion of plastic marine debris by longnose lancetfish (Alepisaurus ferox) in the North Pacific Ocean. Marine Pollution Bulletin 69:97-104.

Koelmans, A. A., E. Besseling, A. Wegner, and E. M. Foekema. 2013. Plastic as a carrier of POPs to aquatic organisms: A model analysis. Environmental Science \& Technology. Published online June 11, 2013.

Kremer, P., and L. P. Madin. 1992. Particle retention efficiency of salps. Journal of Plankton Research 14:1009-1015. 
Kukulka, T., G. Proskurowski, S. Morét-Ferguson, D. W. Meyer, and K. L. Law. 2012. The effect of wind mixing on the vertical distribution of buoyant plastic debris. Geophysical Research Letters 39:6 pp.

Laist, D. 1997. Impacts of marine debris: entanglement of marine life in marine debris including a comprehensive list of species with entanglement and ingestion records. Pages 99-140 in J. Coe and D. Rogers, editors. Marine debris: sources, impact and solutions. Springer, New York.

Law, K. L., S. Moret-Ferguson, N. A. Maximenko, G. Proskurowski, E. E. Peacock, J. Hafner, and C. M. Reddy. 2010. Plastic accumulation in the North Atlantic Subtropical Gyre. Science 329:1185-1188.

Lusher, A. L., M. McHugh, and R. C. Thompson. 2013. Occurrence of microplastics in the gastrointestinal tract of pelagic and demersal fish from the English Channel. Marine Pollution Bulletin 67:94-99.

Moore, C. J., S. L. Moore, M. K. Leecaster, and S. B. Weisberg. 2001. A comparison of plastic and plankton in the North Pacific central gyre. Marine Pollution Bulletin 42:1297-1300.

Von Moos, N., P. Burkhardt-Holm, and A. Köhler. 2012. Uptake and effects of microplastics on cells and tissue of the blue mussel Mytilus edulis L. after an experimental exposure. Environmental Science \& Technology 46:11327-11335.

Moret-Ferguson, S., K. L. Law, G. Proskurowski, E. K. Murphy, E. E. Peacock, and C. M. Reddy. 2010. The size, mass, and composition of plastic debris in the western North Atlantic Ocean. Marine Pollution Bulletin 60:1873-1878.

Moser, M. L., and D. S. Lee. 1992. A fourteen-year survey of plastic ingestion by western North Atlantic seabirds. Colonial Waterbirds 15:83-94.

Murray, F., and P. R. Cowie. 2011. Plastic contamination in the decapod crustacean Nephrops norvegicus (Linnaeus, 1758). Marine Pollution Bulletin 62:1207-1217.

National Research Council. 2009. Tackling Marine Debris in the 21st Century. National Academies Press, Washington DC.

Nelson, P. A. 2003. Marine fish assemblages associated with fish aggregating devices (FADs): effects of fish removal, FAD size, fouling communities, and prior recruits. Fishery Bulletin 101:835-850.

Newman, W. A., and D. P. Abbott. 1980. Cirripedia: The Barnacles. Pages 504-535 in R. H. Morris, D. P. Abbott, and E. C. Haderlie, editors. Intertidal Invertebrates of California. Stanford University Press, Stanford.

Patel, B. 1959. The influence of temperature on the reproduction and moulting of Lepas anatifera L. under laboratory conditions. Journal of the Marine Biological Association of the United Kingdom 38:589-597.

Possatto, F. E., M. Barletta, M. F. Costa, J. A. Ivar do Sul, and D. V. Dantas. 2011. Plastic debris ingestion by marine catfish: An unexpected fisheries impact. Marine Pollution Bulletin 62:1098-1102.

QGIS Development Team. 2013. QGIS Geographic Information System. Open Source Geospatial Foundation Project.

R Development Core Team. 2012. R: A language and environment for statistical computing. Vienna, Austria.

Rasband, W. S. 2012. ImageJ. U. S. National Institutes of Health, Bethesda MD.

Rios, L., P. Jones, C. Moore, and U. Narayan. 2010. Quantitation of persistent organic pollutants adsorbed on plastic debris from the Northern Pacific Gyre's "eastern garbage patch". Journal of Environmental Monitoring 12:2226-2236.

Rios, L. M., C. Moore, and P. R. Jones. 2007. Persistent organic pollutants carried by synthetic polymers in the ocean environment. Marine Pollution Bulletin 54:1230-1237. 
402

403

404

405

406

407

408

409

410

411

412

413

414

415

416

417

418

419

420

421

422

423

424

425

426

427

428

429

430

431

432

433

434

435

436

437

438

439

440

441

442

443

444

445

446

447

448

Ritz, D. A. 2008. Gut residence time in pelagic crustaceans. Journal of the Marine Biological Association of the United Kingdom 88:65-67.

Rochman, C. M., E. Hoh, B. T. Hentschel, and S. Kaye. 2013. Long-term field measurement of sorption of organic contaminants to five types of plastic pellets: Implications for plastic marine debris. Environmental Science \& Technology 47:1646-1654.

Ryan, P. G. 2008. Seabirds indicate changes in the composition of plastic litter in the Atlantic and south-western Indian Oceans. Marine Pollution Bulletin 56:1406-1409.

Ryan, P. G., C. J. Moore, J. A. van Franeker, and C. L. Moloney. 2009. Monitoring the abundance of plastic debris in the marine environment. Philosophical Transactions of the Royal Society B 364:1999-2012.

Schuyler, Q., B. D. Hardesty, C. Wilcox, and K. Townsend. 2013. Global analysis of anthropogenic debris ingestion by sea turtles. Conservation Biology. Published online 5 August 2013.

Sievert, P. R., and L. Sileo. 1993. The effects of ingested plastic on growth and survival of albatross chicks. in K. Vermeer, K. T. Briggs, K. H. Morgan., and D. Siegel-Causey, editors. The status, ecology, and conservation of marine birds of the North Pacific. Canadian Wildlife Service Special Publications, Ottawa.

Sileo, L., P. Sievert, and M. Samuel. 1990. Causes of mortality of albatross chicks at Midway Atoll. Journal of Wildlife Diseases 26:329-338.

Spear, L. B., D. G. Ainley, and C. A. Ribic. 1995. Incidence of plastic in seabirds from the tropical pacific, 1984-1991: Relation with distribution of species, sex, age, season, year and body weight. Marine Environmental Research 40:123-146.

STAP-GEF. 2011. Marine Debris as a Global Environmental Problem: Introducing a solutions based framework focused on plastic. $28 \mathrm{pp}$. STAP Information Document, Scientific and Technical Advisory Panel, Global Environment Facility, Washington DC.

Teuten, E. L., J. M. Saquing, D. R. U. Knappe, M. A. Barlaz, S. Jonsson, A. Bjorn, S. J. Rowland, R. C. Thompson, T. S. Galloway, R. Yamashita, D. Ochi, Y. Watanuki, C. Moore, V. Pham Hung, T. S. Tana, M. Prudente, R. Boonyatumanond, M. P. Zakaria, K. Akkhavong, Y. Ogata, H. Hirai, S. Iwasa, K. Mizukawa, Y. Hagino, A. Imamura, M. Saha, and H. Takada. 2009. Transport and release of chemicals from plastics to the environment and to wildlife. Philosophical Transactions of the Royal Society of London B 364:2027-2045.

Thiel, M., and L. Gutow. 2005a. The ecology of rafting in the marine environment I: The floating substrata. Oceanography and Marine Biology: An Annual Review 42:181-263.

Thiel, M., and L. Gutow. 2005b. The ecology of rafting in the marine environment II: The rafting organisms and community. Oceanography and Marine Biology: An Annual Review 43:279-418.

Thompson, R. C., Y. Olsen, R. P. Mitchell, A. Davis, S. J. Rowland, A. W. G. John, D. McGonigle, and A. E. Russell. 2004. Lost at sea: Where is all the plastic? Science 304:838.

Tsikhon-Lukanina, E. A., O. G. Reznichenko, and G. G. Nikolaeva. 2001. Ecology of invertebrates on the oceanic floating substrata in the northwest Pacific ocean. Oceanology 41:525-530.

U.S. Environmental Protection Agency. 2011. Marine Debris in the North Pacific: A summary of existing information and identification of data gaps. Page 23. Pacific Southwest/Region 9, San Francisco, CA.

Ugolini, A., G. Ungherese, M. Ciofini, A. Lapucci, and M. Camaiti. 2013. Microplastic debris in sandhoppers. Estuarine, Coastal and Shelf Science. Published online 15 June 2013. 
449

450

451

452

453

454

455

456

457

458

459

460

461

462
Vassilopoulou, V., A. Siapatis, G. Christides, and P. Bekas. 2004. The biology and ecology of juvenile pilotfish (Naucrates ductor) associated with Fish Aggregating Devices (FADs) in eastern Mediterranean waters. Mediterranean Marine Science 5:61-70.

Wegner, A., E. Besseling, E. M. Foekema, P. Kamermans, and A. A. Koelmans. 2012. Effects of nanopolystyrene on the feeding behavior of the blue mussel (Mytilus edulis L.). Environmental Toxicology and Chemistry 31:2490-2497.

Wilson, D. S. 1973. Food size selection among copepods. Ecology 54:909-914.

Wong, C. S., D. R. Green, and W. J. Cretney. 1974. Quantitative tar and plastic waste distributions in Pacific Ocean. Nature 247:30-32.

Wright, S. L., R. C. Thompson, and T. S. Galloway. 2013. The physical impacts of microplastics on marine organisms: a review. Environmental Pollution 178:483-492.

Yamashita, R., H. Takada, M. Fukuwaka, and Y. Watanuki. 2011. Physical and chemical effects of ingested plastic debris on short-tailed shearwaters, Puffinus tenuirostris, in the North Pacific Ocean. Marine Pollution Bulletin 62:2845-2849. 


\section{Figure 1}

Barnacles and ingestion microplastic.

A) A dense aggregation of Lepas spp. barnacles growing on a buoy and attached line, collected in October 2012. B) Basic anatomy of Lepas denoting the capitulum, which includes the body and its enclosing plates, and the peduncle, the muscular stalk that attaches the barnacle to the substrate. C) Microplastic ingested by an individual barnacle. 

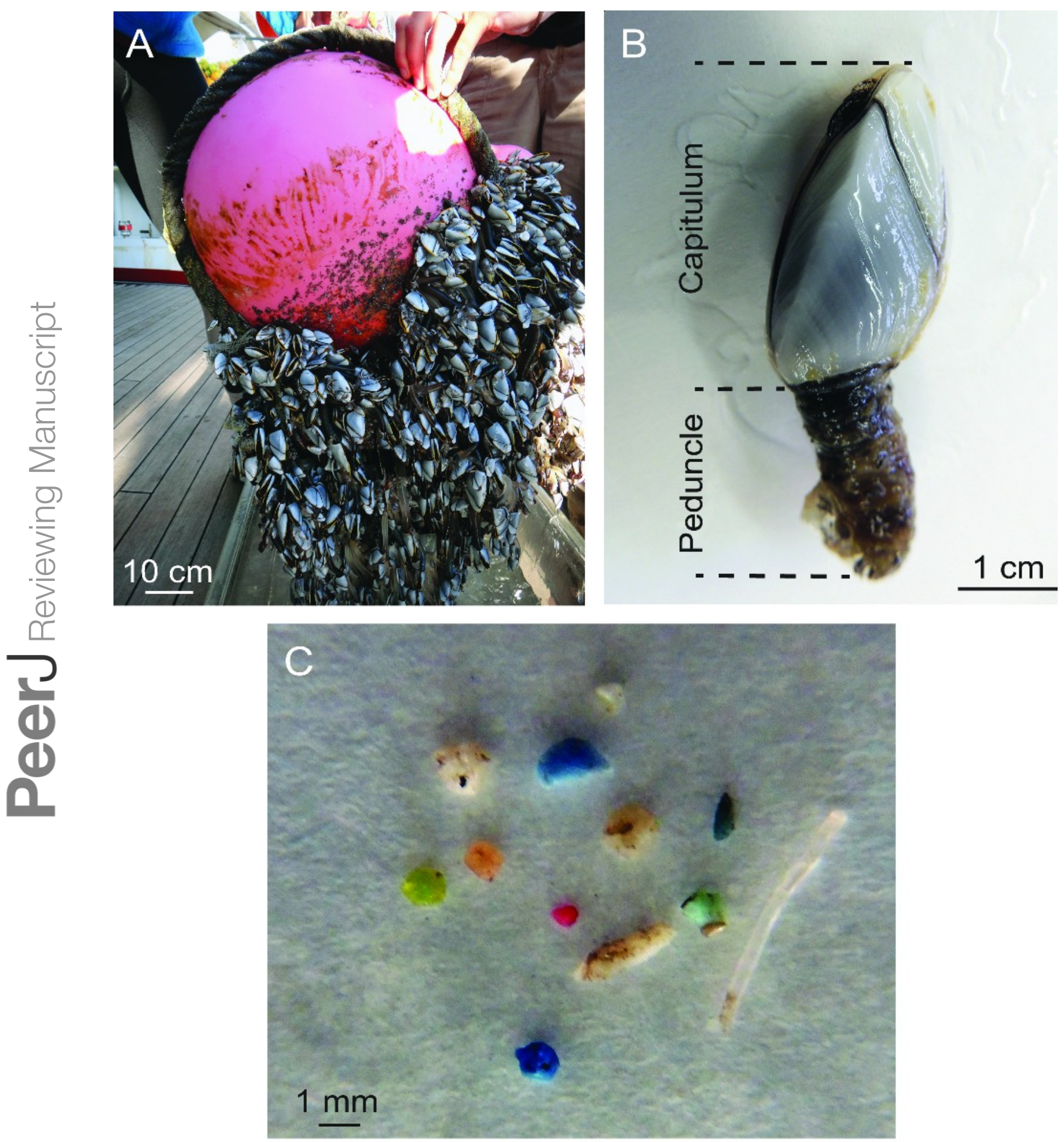


\section{Figure 2}

Ingestion of microplastic by barnacles across the study area.

Circles indicate sampling stations and dark fill indicates the proportion of barnacles that had ingested microplastic at each site. Station coordinates, sample sizes, and ingestion proportions are given in Table 1.

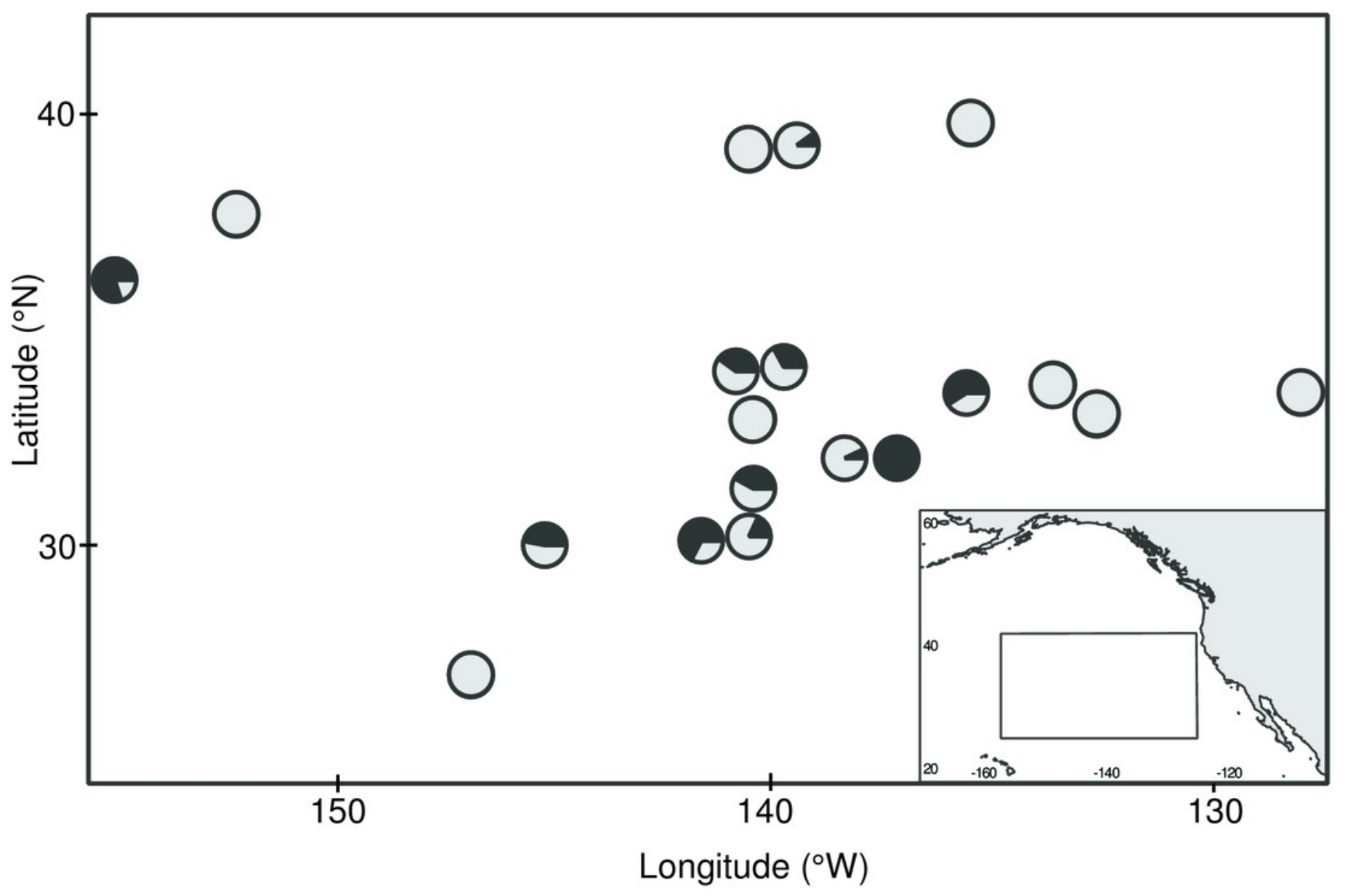




\section{Figure 3}

Number of microplastic particles ingested by barnacles.

A) Frequency distribution of microplastic pellets ingested by individual lepadid barnacles

$(\mathrm{N}=385)$. B) Frequency distribution of ingestion by capitulum length $(\mathrm{N}=369$; sample size is smaller than above since capitulum length was not measured for 16 barnacles). Black bars are the number of individual barnacles that ingested plastic and grey bars are the number of individual barnacles that did not ingest plastic. Bins of capitulum length are greater than the first value, and less than or equal to the second value (e.g., $>0.5 \mathrm{~cm}$ and $<=1.0 \mathrm{~cm}$ ).

Percentages of ingestion by size class are as follows: 6.7\%, 0, 23.2\%, 43.9\%, 45.2\%, 35.3\%, $25.0 \%, 40.0 \%, 0$. 

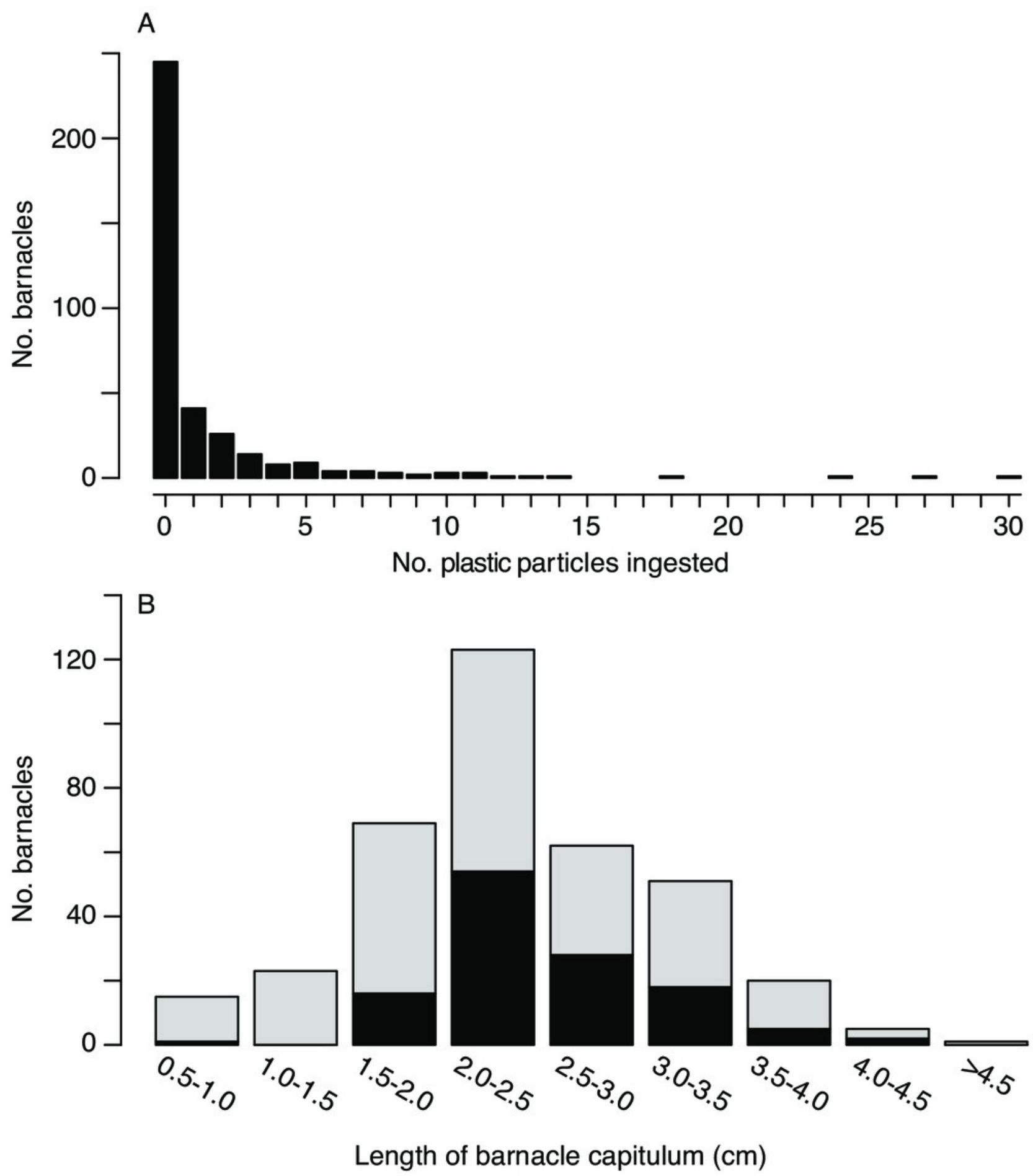


\section{Figure 4}

Size of microplastic particles ingested by barnacles.

Size-frequency distributions for A) maximum diameter and B) two-dimensional surface area of particles ingested by barnacles (black; $\mathrm{N}=507$ ) compared to of all microplastic particles collected in 2009 (grey; $\mathrm{N}=30,518$ ). Note: 518 microplastic particles were recovered from barnacles, but 11 were lost before they could be photographed for this analysis. 

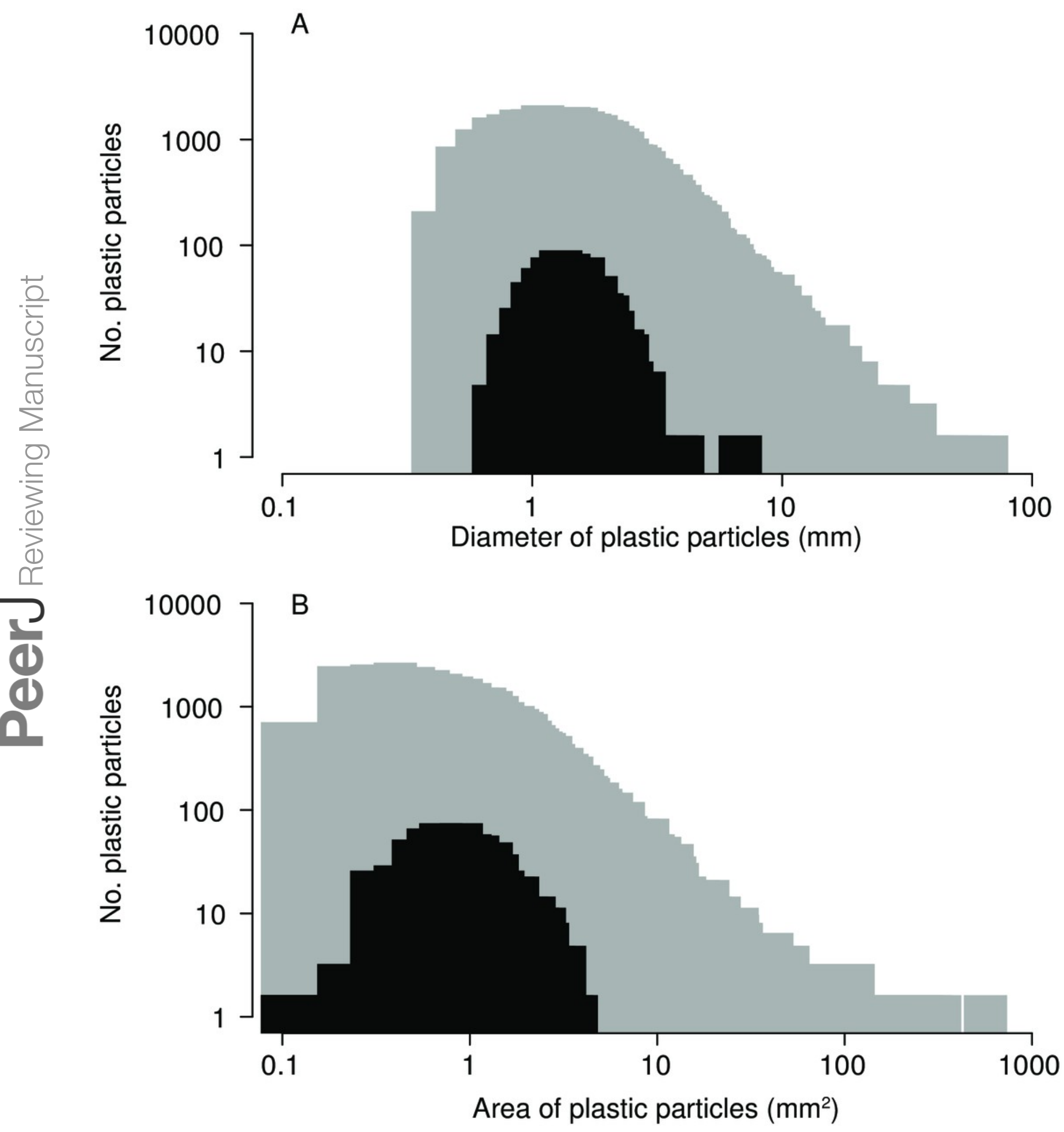


\section{Table 1 (on next page)}

Station locations and proportion of microplastic ingestion. 


\begin{tabular}{|l|l|l|l|l|l|l|}
\hline Station ID & $\begin{array}{l}\text { Date of } \\
\text { collection }\end{array}$ & Latitude $\left({ }^{\circ} \mathbf{N}\right)$ & Longitude $\left({ }^{\circ} \mathbf{W}\right)$ & $\begin{array}{l}\text { Total no. } \\
\text { barnacles }\end{array}$ & $\begin{array}{l}\text { Proportion } \\
\text { with plastic }\end{array}$ & $\begin{array}{l}\text { Proportion } \\
\text { without } \\
\text { plastic }\end{array}$ \\
\hline S242-021-DN & 1-Jul-12 & 36.135 & 154.957 & 5 & 0.80 & 0.20 \\
\hline S242-023-DN & 2-Jul-12 & 37.672 & 152.163 & 20 & 0.00 & 1.00 \\
\hline S243-083-DN & $31-$ Oct-12 & 27.000 & 146.782 & 10 & 0.00 & 1.00 \\
\hline S243-069-DN & $27-O c t-12$ & 30.057 & 145.057 & 15 & 0.47 & 0.53 \\
\hline $\begin{array}{l}\text { S243-055-057- } \\
\text { 058-DN }\end{array}$ & 24-Oct-12 & 30.140 & 141.220 & 80 & 0.68 & 0.33 \\
\hline $\begin{array}{l}\text { S243-051-052- } \\
\text { DN }\end{array}$ & 23-Oct-12 & 30.230 & 140.690 & 34 & 0.18 & 0.82 \\
\hline U39.F32 & 15-Aug-09 & 34.076 & 140.474 & 53 & 0.40 & 0.60 \\
\hline S243-046-DN & 22-Oct-12 & 31.330 & 140.338 & 52 & 0.42 & 0.58 \\
\hline S3.F6 & 10-Aug-09 & 32.911 & 140.320 & 2 & 0.00 & 1.00 \\
\hline S242-031-NT & 6-Jul-12 & 39.178 & 140.160 & 12 & 0.00 & 1.00 \\
\hline S4.F30-F26 & 14-Aug-09 & 34.090 & 139.870 & 9 & 0.33 & 0.67 \\
\hline S242-032-DN & 6-Jul-12 & 39.270 & 139.570 & 10 & 0.10 & 0.90 \\
\hline $\begin{array}{l}\text { S2.F22- } \\
\text { U40.F11 }\end{array}$ & 9-Aug-09 & 32.050 & 137.928 & 15 & 0.07 & 0.93 \\
\hline F13 & 9-Aug-09 & 32.075 & 137.223 & 1 & 1.00 & 0.00 \\
\hline S243-032-DN & 16-Oct-12 & 33.563 & 135.432 & 17 & 0.59 & 0.41 \\
\hline S242-035-DN & 8-Jul-12 & 39.717 & 135.325 & 10 & 0.00 & 1.00 \\
\hline $\begin{array}{l}\text { S243-025-027- } \\
\text { DN }\end{array}$ & 14-Oct-12 & 33.700 & 133.460 & 13 & 0.00 & 1.00 \\
\hline S243-023-DN & 13-Oct-12 & 33.051 & 132.445 & 14 & 0.00 & 1.00 \\
\hline S243-011-DN & 9-Oct-12 & 33.493 & 127.715 & 13 & 0.00 & 1.00 \\
\hline
\end{tabular}

